\title{
Time dependence of immersion freezing: an experimental study on size selected kaolinite particles
}

\author{
A. Welti ${ }^{1}$, F. Lüönd ${ }^{1,2}$, Z. A. Kanji ${ }^{1}$, O. Stetzer ${ }^{1}$, and U. Lohmann ${ }^{1}$ \\ ${ }^{1}$ ETH Zurich, Institute for Atmospheric and Climate Science, Switzerland \\ ${ }^{2}$ Federal Office of Metrology, Bern, Switzerland
}

Correspondence to: A. Welti (andre.welti@env.ethz.ch)

Received: 26 April 2012 - Published in Atmos. Chem. Phys. Discuss.: 16 May 2012

Revised: 7 October 2012 - Accepted: 8 October 2012 - Published: 29 October 2012

\begin{abstract}
The time dependence of immersion freezing was studied for temperatures between $236 \mathrm{~K}$ and $243 \mathrm{~K}$. Droplets with single immersed, size-selected $400 \mathrm{~nm}$ and $800 \mathrm{~nm}$ kaolinite particles were produced at $300 \mathrm{~K}$, cooled down to supercooled temperatures, and the fraction of frozen droplets with increasing residence time was detected. To simulate the conditions of immersion freezing in mixed-phase clouds we used the Zurich Ice Nucleation Chamber (ZINC) and its vertical extension, the Immersion Mode Cooling chAmber (IMCA). We observed that the frozen fraction of droplets increased with increasing residence time in the chamber. This suggests that there is a time dependence of immersion freezing and supports the importance of a stochastic component in the ice nucleation process. The rate at which droplets freeze was observed to decrease towards higher temperatures and smaller particle sizes. Comparison of the laboratory data with four different ice nucleation models, three based on classical nucleation theory with different representations of the particle surface properties and one singular, suggest that the classical, stochastic approach combined with a distribution of contact angles is able to reproduce the ice nucleation observed in these experiments most accurately. Using the models to calculate the increase in frozen fraction at typical mixed-phase cloud temperatures over an extended period of time, yields an equivalent effect of $-1 \mathrm{~K}$ temperature shift for an increase in times scale by one order of magnitude. This suggests that temperature is more important than time.
\end{abstract}

\section{Introduction}

The formation of ice crystals in supercooled clouds is usually initiated on the surface of ice nucleating particles (IN), e.g. mineral dust aerosols blown off from arid surfaces (Kumai, 1951; Isono et al., 1959; DeMott et al., 2003b; Eastwood et al., 2008).

One pathway of ice crystal formation is by ice nuclei acting as cloud condensation nuclei $(\mathrm{CCN})$ at temperatures above $273 \mathrm{~K}$, subsequent cooling of the cloud droplets and nucleation of ice at a certain degree of supercooling. If ice forms heterogeneously on the IN surface the process is referred to as immersion freezing. This is an important freezing mechanism down to a supercooling of approximately $235 \mathrm{~K}$ below which homogeneous freezing within the droplet volume becomes the more efficient mode of ice nucleation (Pruppacher and Klett, 1997). Other ice nucleation modes like deposition nucleation, condensation- and contact freezing (Vali, 1985) can also be active in supercooled clouds.

In mixed-phase clouds, observations corroborate that immersion freezing is the dominant freezing mechanism. For example Ansmann et al. (2009) reported lidar observations of tropical altocumulus clouds that consistently showed the occurence of liquid droplets prior to ice formation. They conclude that ice formation via condensation and deposition nucleation are not important ice formation mechanisms for mixed-phase clouds. The recent laboratory study by Bunker et al. (2012) reported that hundreds of collisions of mineral dust particles with a supercooled droplet are needed to initiate contact freezing. However the number of unimmersed particles in mixed-phase clouds can be expected to be low compared to the number of droplets (Wiacek and Peter, 2009). This suggests that contact freezing is likely not a dominant ice formation pathway in mixed-phase clouds.

Mid-tropospheric clouds which cover about $25 \%$ of the globe (Sassen and Wang, 2012) consist of $61.8 \%$ mixedphase clouds with the highest occurrence in the midlatitudes 
and over the polar oceans (Zhang et al., 2010). In average mixed-phase clouds cover about $15.5 \%$ of the globe.

Immersion freezing in mixed-phase clouds causes the transformation of small cloud droplets to larger ice crystals that precipitate and thereby influences the formation of precipitation and consequently the surface water distribution, e.g. the freezing of liquid water droplets in mixed-phase clouds is one of the essential processes for precipitation formation in midlatitudes (Houghton, 1950).

The change in the cloud brightness resulting from the freezing of cloud droplets has an effect on the Earth's surface energy budget (Cantrell and Heymsfield, 2005; Lohmann, 2002). Additionally to the freezing of droplets, the cloud radiative properties are influenced by the depletion of liquid water via the Bergeron-Findeisen process in partially glaciated clouds which effects the size of the remaining droplets (Westbrook and Illingworth, 2009).

To predict the radiative properties and precipitation development of mixed-phase clouds, a detailed understanding of the mechanisms by which droplets freeze is paramount. In particular, the question of whether the fraction of ice and liquid water depends on time or solely on temperature has not been answered definitively by experiments. Two theories of immersion freezing have been discussed since the 1950's.

First, the "stochastic hypothesis" formulated by Bigg (1953) which is based on the concept that, within supercooled water, thermal fluctuations of water molecules can produce clusters which resemble the structure of ice. By capturing and losing molecules, some of these ice germs grow to a size (characterised by the critical radius) where they become stable and initiate freezing. Subsequent freezing of a droplet and development of the macroscopic ice crystal emanates from the ice-water interface of the first critical germ. The number of molecules required to form a stable ice germ within a droplet decreases with increasing supercooling. Therefore the probability of critical germ formation increases towards lower temperatures. Also the presence of a particle surface in a supercooled droplet reduces the amount of water molecules that are needed to reach the stable cluster radius by allowing the germ to form on it as a spherical cap. The number of critical ice germs forming per unit time and unit surface area of the IN is referred to as the nucleation rate. This stochastic approach is known as the classical nucleation theory (CNT).

The second, "singular hypothesis" proposed by Langham and Mason (1958) assumes that at a given supercooling, the radius of ice germ forming on the aerosol surface is determined by surface features, and thermal fluctuations have negligible influence on the ice germ radius. If an ice germ reaches the critical germ radius at the given supercooling, the droplet freezes immediately. Otherwise the droplet will stay liquid irrespective of the time during which the droplet is exposed to the given supercooling.

Experimental support for both a stochastic and a singular component in immersion freezing has been found. A time dependence of ice nucleation was observed and described by Vonnegut (1949) and has been supported by a number of consecutive cloud chamber studies, mainly on AgI (e.g. Fletcher, 1959; Wartburton and Heffernan, 1964). Evidence that time dependence could be negligible, comes from experiments in which the freezing of droplets was investigated at various cooling rates but no time lag in the number of frozen droplets could be observed (Vali, 1994, and references therein).

Recent immersion freezing studies on cold stages used a range of different cooling rates, exposure of suspension droplets to isothermal conditions for up to $10 \mathrm{~min}$ (Murray et al., 2011; Broadley et al., 2012) or repeated exposure of the same sample to low temperatures (Vali, 2008). All these studies observed a time dependence of ice formation. Differential scanning caliometry (DSC) measurements of oil/water emulsion samples (Pinti et al., 2012), found evidence of varying onset freezing temperatures when measurements where repeated with the same sample. This supports the stochastic approach. On the other hand experiments with a large number of droplets that contained single nuclei as performed in cloud- or diffusion chambers (Connolly et al., 2009; Niedermeier et al., 2011), reported a more singular freezing behaviour. In the cold stage study of Vali and Stansbury (1966) it was concluded that neither a purely stochastic nor a singular description is applicable to represent the probability of ice nucleation at a constant temperature.

To represent ice nucleation in numerical climate models accurately it is useful to know which hypothesis is suitable for a certain particle population.

The current study uses the same experimental setup as was used by Lüönd et al. (2010) to investigate the size dependence of immersion freezing on kaolinite particles. The measurements reported by Lüönd et al. (2010) were done at a constant residence time in the supercooled region of the experiment. Fitting the experimental data with either an active site stochastic or singular model revealed a comparable difference of the fit curves from the measurements. They proposed that time-dependent measurements could help assess the differences and applicability of the two approaches in representing immersion freezing.

Based on the results and recommendation of Lüönd et al. (2010), we investigate the nature of time-dependence in immersion freezing by measuring the frozen fraction of a large number of droplets containing single immersed particles by varying residence times while keeping the experimental temperature constant. In a second step described in Sect. 4, we tested a stochastic, a singular and two modified-stochastic model formulations for their ability to represent the measured data. Based on the best fit of each model we then calculated the glaciation state of a mixed-phase cloud after $30 \mathrm{~min}$ at a constant temperature, which corresponds to a typical time step in a global climate model. To simplify the experimental findings, we derived apparent, temperature dependent contact angles that might incorporate the non-stochastic component of freezing in an otherwise purely stochastic 


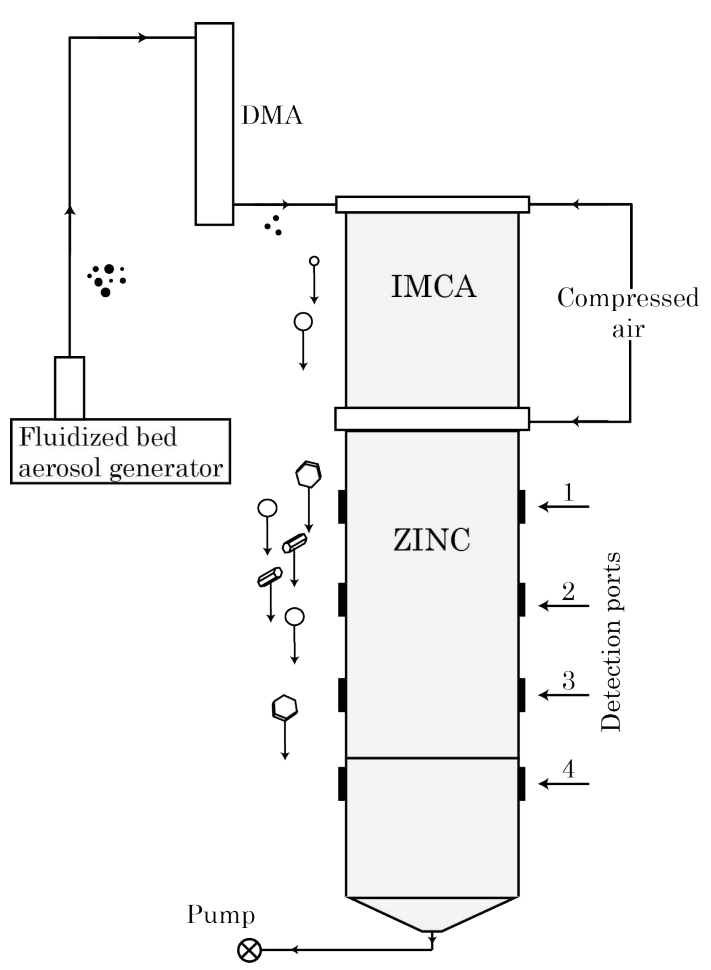

Fig. 1. Schematic of the experimental setup. A fluidized bed aerosol generator is used to produce mineral dust aerosol. Particles with $400 \mathrm{~nm}$ and $800 \mathrm{~nm}$ diameter are selected with a DMA. In the top of IMCA particles activate as $\mathrm{CCN}$ at $300 \mathrm{~K}$ before they are continuously cooled down to the freezing temperature prevailing in ZINC. In the transition from IMCA to ZINC additional sheath air is introduced to counteract buoyant displacement of the droplets from the centre position. In ZINC the droplets are exposed to cold temperatures and eventually the immersed particles cause the droplets to freeze. The time-dependent frozen fraction is detected with IODE consecutively at the four detection ports.

formulation. Such a formulation might be useful for climate models due to its relative simplicity. In addition, we calculated the median freezing temperature as a function of the surface area of the aerosol for the five models, to compare them to the experimental data.

\section{Experimental method}

The Zurich Ice Nucleation Chamber (ZINC) (Stetzer et al., 2008), a parallel plate continuous flow diffusion chamber (CFDC) following the working principle first described by Rogers (1988) with the vertical extension Immersion Mode Cooling chAmber (IMCA) (Lüönd et al., 2010) was used to study the time dependence of immersion freezing. A schematic of the experimental setup is shown in Fig. 1. The IMCA/ZINC combination allows to mimic a quasi-realistic pathway of immersion freezing by activating the aerosol as $\mathrm{CCN}$ at temperatures above $273 \mathrm{~K}$, cooling the droplets down to supercooled temperatures and investigate immersion freezing at constant temperatures and at water saturated conditions for the residence time in the ZINC chamber. The constant temperature and saturation conditions in ZINC represent conditions of a static mixed-phase cloud.

The frozen fraction of droplets containing single immersed kaolinite particles was detected with the Ice Optical DEpolarization detector (IODE) described in Nicolet et al. (2010).

\subsection{Aerosol generation and droplet activation}

Kaolinite (Fluka) particles were aerosolised in a Fluidized Bed Aerosol Generator (TSI Model 3400A) and size selected according to their electrostatic mobility with a Differential Mobility Analyser (DMA, TSI Model 3081). To confine the size distribution of the aerosol generated by the fluidized bed aerosol generator, a cascade of two cyclones and two parallel operated impactors were introduced into the particle stream before the DMA (not shown in Fig. 1). The resulting removal of large particles from the initial size distribution ensures a minimum contribution from multiple charged particles to the selected aerosol size for the experiments. Moreover, it has been shown in the study of Welti et al. (2009), that the selected sizes of $400 \mathrm{~nm}$ and $800 \mathrm{~nm}$ are in the downslope of the size distribution produced by the aerosol generator, so the contribution of larger double or triple charged particles with an equal electrical mobility diameter is below $10 \%$.

The size selected aerosol is sampled by the IMCA chamber. The inner walls of IMCA are lined with wet filter paper, and a horizontal and vertical temperature gradient is applied to generate water supersaturation at high temperatures in the top part and water saturation at its bottom at temperatures close to the experimental freezing temperatures applied in ZINC. In the top part of IMCA the mineral particles act as $\mathrm{CCN}$ at $300 \mathrm{~K}$ and water supersaturations up to $20 \%$ (therefore we assume all particles are immersed). Along their travel through IMCA, the particles which are now immersed in droplets, are cooled down to the experimental temperature applied in ZINC.

\subsection{Freezing experiments}

In the ZINC chamber the droplets are exposed to freezing temperatures between $236 \mathrm{~K}$ and $244 \mathrm{~K}$ which are atmospherically relevant glaciation temperatures for mixed-phase clouds as supercooled cloud droplets can exist down to approximately $235 \mathrm{~K}$ (Pruppacher and Klett, 1997). The uncertainty in the reported temperature is on the order of $\pm 0.3 \mathrm{~K}$, mainly determined by the temperature gradient across the sample layer. The aerosol sample is sandwiched between two layers of particle free sheath-air to control its width and lateral position between the walls. The front and back wall of ZINC are covered with an ice layer and held at two different temperatures to generate water saturation at the sample position. The water saturated conditions prevent evaporation or 


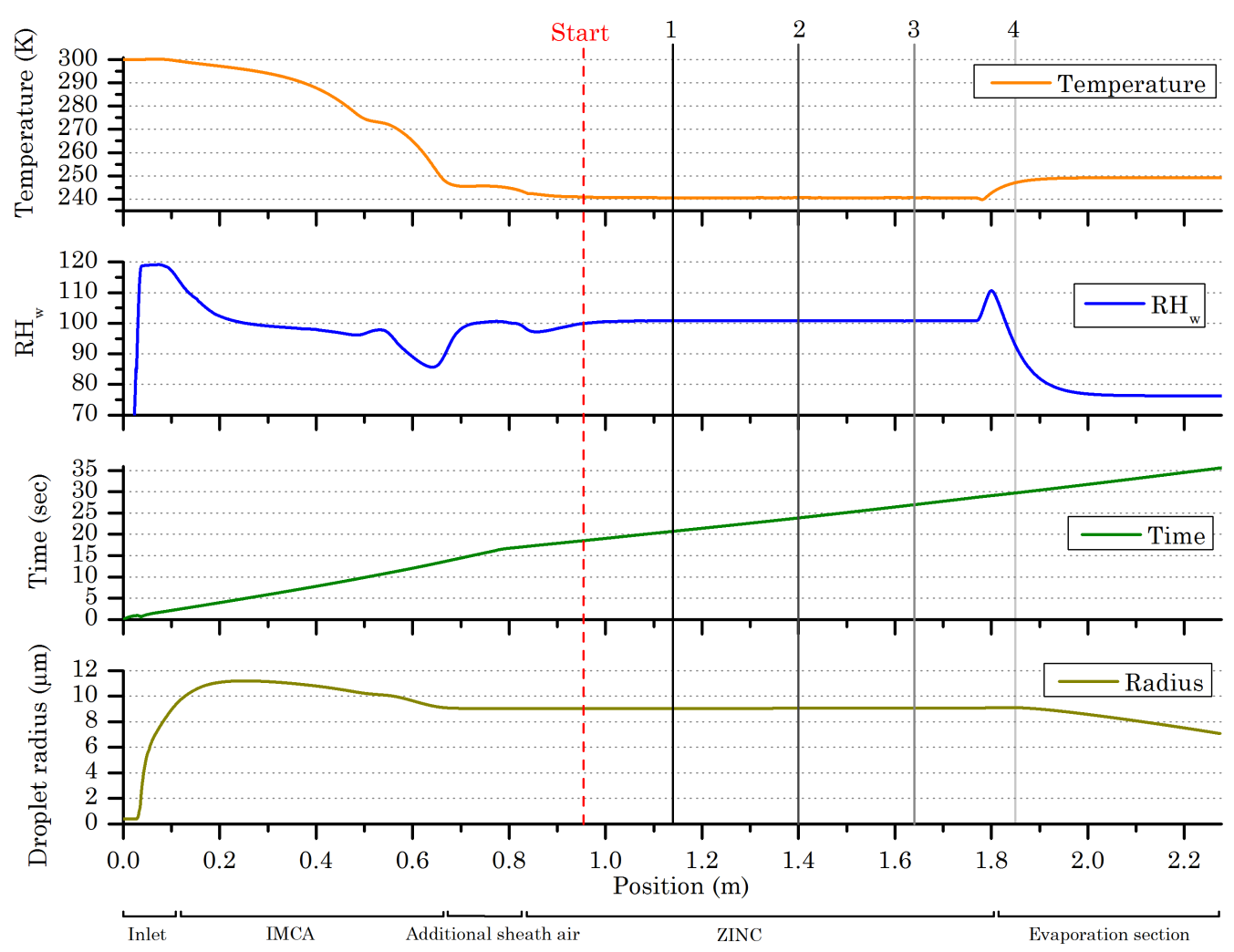

Fig. 2. Experimental conditions along a particle trajectory in the sample air obtained from FLUENT simulations. From top to down the air temperature, relative humidity with respect to water, residence time and calculated droplet size are shown with respect to the vertical location in the experiment. The corresponding parts are labeled at the bottom. The vertical red line indicates the position from where nucleation time was counted. Vertical grey lines numbered with 1-4 show the positions of detection of the frozen fraction.

condensation of the droplets which ensures that the droplet temperature is very close to the air temperature.

The temperature and saturation conditions at the sample position between the warm and the cold wall of ZINC are calculated from the wall temperature difference and the fact that the water vapour pressure at both walls equals the saturation vapour pressure of ice at the respective temperature.

Figure 2 shows the temperature and saturation condition in the sample layer for one example experiment at $240 \mathrm{~K}$ and a flow velocity of $51 / \mathrm{min}$ in IMCA and $101 / \mathrm{min}$ in ZINC. Technical details on IMCA and ZINC can be found in the work of Lüönd et al. (2010) and Stetzer et al. (2008), respectively.

To investigate the effect of time on immersion freezing, the IODE detector was mounted at four different positions (indicated in Fig. 1) on the ZINC chamber and three different flow conditions given in Table 1 were applied to alter the residence time of the supercooled droplets within the ZINC chamber. Detecting the frozen fraction with the IODE detector (see Sect. 2.4) at the four positions of ZINC allowed us to pursue the evolution of the fraction of frozen droplets as a function of residence time at constant temperatures.

Residence time was counted starting from stable temperature and saturation conditions in ZINC as indicated in Fig. 2.
Table 1. Residence time in ZINC before the frozen fraction was detected in dependence of position of detection and total flow.

\begin{tabular}{lcccr}
\hline Flow & Position 1 & Position 2 & Position 3 & Position 4 \\
\hline $191 / \mathrm{min}$ & $1.1 \mathrm{~s}$ & $2.3 \mathrm{~s}$ & - & - \\
$101 / \mathrm{min}$ & $3.0 \mathrm{~s}$ & $5.9 \mathrm{~s}$ & $8.9 \mathrm{~s}$ & $10.3 \mathrm{~s}$ \\
$51 / \mathrm{min}$ & - & - & - & $21.4 \mathrm{~s}$ \\
\hline
\end{tabular}

The droplets are exposed to supercooled temperatures already before they reach stable conditions. This transition where droplets are cooled to the experimental temperature prevailing in ZINC induces a systematic uncertainty in the reported nucleation time of up to $2 \mathrm{~s}$ where nucleation might occur at higher temperatures. Droplets adjust to the ambient temperature within $0.3 \mathrm{~s}$. Detection positions $1-3$ are located at the freezing section of ZINC, whereas detection port 4 is at the beginning of the evaporation section. As can be seen from Fig. 2, temperature and relative humidity change in the transition from the freezing to the evaporation section. The reported time for nucleation might therefore be $1 \mathrm{~s}$ shorter what could lead to a small systematic bias in the reported frozen fraction towards lower ratios at position 4 . 


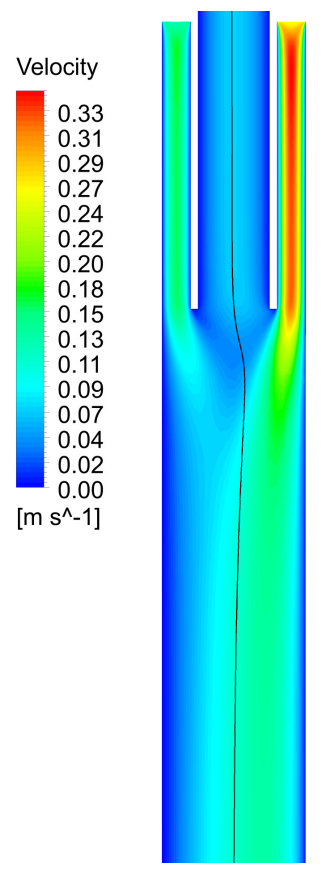

Fig. 3. Flow velocity in the additional sheath air. The additional flow is adjusted to counteract the buoyant displacement of the aerosol layer, depending on $\Delta \mathrm{T}$ between the cold and the warm wall in ZINC. The black line indicates an example particle trajectory.

\subsection{Modifications of the experimental setup as compared to Lüönd et al. (2010)}

In the transition between IMCA and ZINC asymmetric additional sheath air is introduced to counteract the displacement of the sample layer towards the cold wall due to the superposition of the laminar and the buoyant flow created by the temperature gradient in ZINC. The addition of a higher flow of sheath air on the cold side counters the buoyant displacement and ensures that the sample flow remains in the centre of ZINC where the ice-water fraction can be detected by the IODE detector. Fig. 3 shows a Fluent simulation of the flow velocity profile in the transition region from IMCA to ZINC where the additional sheath air is introduced. An additional advantage of this improvement is, that IMCA and ZINC can be operated at different total flow rates i.e. a low flow in IMCA to increase the drop growth time and adjustable higher flow-rates in ZINC to vary the residence time for ice nucleation (cf. Table 1).

\subsection{Detection and discrimination of droplets and ice}

To detect the fraction of liquid droplets and ice crystals, the depolarization detector IODE (Nicolet et al., 2010) was used. Linearly polarized laser light is aligned to the sample layer passing through ZINC. Frozen droplets are known to depolarize polarized light, especially if they develop an aspherical shape, whereas liquid droplets do not. The intensity of light backscattered by the frozen and unfrozen droplets is split into its components parallel and perpendicular to the incident polarization by a Wollaston prism and the depolarization is registered. Experiments were repeated up to seven times and average values are reported. For each measurement the background signal of the IODE detector was determined and subtracted. The background signal stems from reflections in ZINC, internal reflections within IODE and eventually inactivated, dry aerosol particles. It has been reported in Lüönd et al. (2010) that the latter do not generate a signal sufficiently strong to be counted by the peak detection algorithm. More details about the components and functionality of IODE can be found in the work of Nicolet et al. (2010). Error bars shown in Fig. 4, 5 and 7 represent an uncertainty in the frozen fraction due to the classification (liquid or ice) uncertainty originating from the measurement errors of the IODE detector. Particles are classified to be ice crystals or water droplets due to the depolarization ratio of backscattered polarized incident laser light. The depolarization ratio of each detected particle is allocated with an uncertainty due to the background signal. A threshold depolarization ratio has been determined experimentally (reported in Lüönd et al., 2010). Each depolarization signal is classified according to the depolarization threshold. If the depolarization threshold lies within a one sigma standard deviation of the signal uncertainty, the particle is counted as potentially misclassified. Error bars are calculated as the ratio of potentially miscounted droplets or ice crystals to the total number of detected particles in the minus and plus direction respectively. For additional details on the signal analysis we refer to Lüönd et al. (2010).

\section{Immersion freezing results}

Size selected, single immersed kaolinite particles have been tested for their ice nucleation efficiency by measuring the temperature dependent frozen fraction for variable residence times. Generally the frozen fraction of droplets containing similar sized kaolinite particles increases towards the homogeneous freezing temperature. This is likely due to the decreasing radius of the critical ice embryo. Variations in the surface features of the individual particles which catalyse the formation of a critical ice embryo cause a distribution in the nucleation activity at a given temperature. The rather steep increase in the temperature dependent frozen fraction as shown in Fig. 4 indicates the small temperature range over which immersion freezing on this type of kaolinite becomes efficient.

\subsection{Size dependence}

Figure 4 shows an example of the detected frozen fraction for two sets of measurements with $400 \mathrm{~nm}$ and $800 \mathrm{~nm}$ kaolinite particles at a constant residence time of $9 \mathrm{~s}$. The 


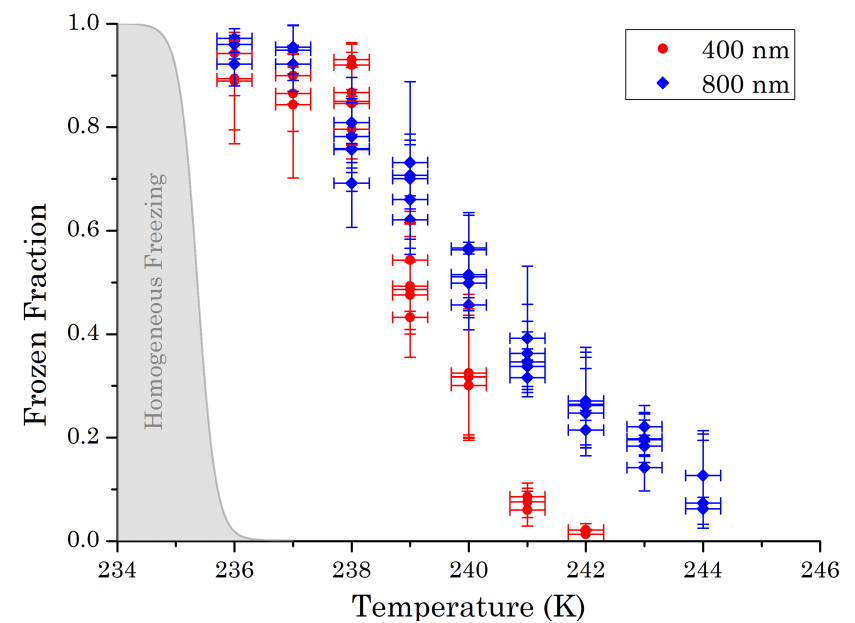

Fig. 4. Temperature dependent frozen fraction of $400 \mathrm{~nm}$ and $800 \mathrm{~nm}$ kaolinite particles for a residence time of 9 seconds. Homogeneous freezing conditions, calculated using the homogeneous nucleation rates reported in Earle et al. (2010), are shaded in grey. Error bars represent the uncertainty in the frozen fraction due to the classification of particles as ice crystals or droplets (see Sect. 2.4 for details).

non-averaged, single-measurement data is shown here to illustrate the dataset from which average values where obtained to compute the fit parameters for the different models (cf. Sect. 4.1). From the single-measurement data the influence of particle size on the onset temperature and frozen fraction at a specific temperature of immersion freezing can be seen. Smaller kaolinite particles tend to be significantly less efficient IN, especially at higher temperatures. The temperature region where immersion freezing on kaolinite particles is active is close to the homogeneous freezing temperature. Compared to homogeneous freezing however, immersion freezing has a gentler slope in the evolution of frozen fraction as a function of temperature. This suggest nucleation kinetics becomes more important towards homogeneous freezing temperatures than surface features reducing the energy barrier of ice nucleation which would be more important towards higher temperatures. This thought is addressed again in Sect. 6.1.

\subsection{Time dependence}

The averaged, time-dependent dataset is shown in Fig. 5. One data point represents the frozen fraction obtained from the depolarisation measurements of up to 10000 single detected droplets/ice crystals.

We observe a time dependent behaviour of the frozen fraction of the immersion freezing process i.e. the frozen fraction increases with increasing residence time in the ZINC chamber. The steepest increase can be observed for short residence times at low temperatures. Warmer temperatures cause a slower but steady increase in the frozen fraction.
From the comparison of the two datasets ( 400 and $800 \mathrm{~nm}$ ) shown in Fig. 5, not only a dependency on the experimental temperature but also a relationship between the surface area and freezing time is observed. In the investigated temperature range, smaller surface areas lead to a stronger dependency on nucleation time i.e. the change in frozen fraction over the residence time in the experiment was larger for the $400 \mathrm{~nm}$ particles. This is in agreement with the work of Gerber (1976) who found that on AgI particles the time dependence of immersion freezing was reduced when the particle size was increased. In summary, we observe immersion freezing to be dependent on temperature, IN surface and time and therefore at least partly a stochastic phenomena.

\section{Analysis of the experimental data with theoretical models}

The stochastic and the singular hypotheses discussed in Sect. 1 can be used to derive theoretical fit functions to the experimental results. By testing if the models can reproduce the experimentally measured frozen fraction as a function of temperature, particle size and time accurately, we aim to determine whether one of the concepts is capable of describing the microphysics of immersion freezing. The model results could then be used to extrapolate the experimentally determined frozen fractions between $\sim 5 \%$ to $95 \%$ to lower frozen fractions, higher temperatures, different particle sizes or time scales. In addition, numerical climate models reached a stage where they are able to incorporate physical representations of the immersion freezing process (e.g. Hoose et al., 2010). Information on what type of formalism is appropriate to describe heterogeneous ice formation in a cloud, will therefore become of interest for modelling studies.

\subsection{Parameterisation of the particle surface}

Following the method described in Lüönd et al. (2010), we test four different approaches to parameterise the particle surfaces for their capability to describe the measured time dependence of immersion freezing. Each model is applied to the combined dataset of $400 \mathrm{~nm}$ and $800 \mathrm{~nm}$ particles. In doing so the obtained fit-parameters are independent of the particle size and represent physical properties of kaolinite particles. One set of parameters is therefore sufficient to derive the frozen fraction of any particle size and temperature. To simplify the analysis of the measurements, the particles are considered to be spherical. With this assumption, the true surface area of the particles is underestimated to some extent.

The four models are summarized in Sect. 4.2 to 4.3. A more detailed discussion of the four approaches can be found in Lüönd et al. (2010). 
a)

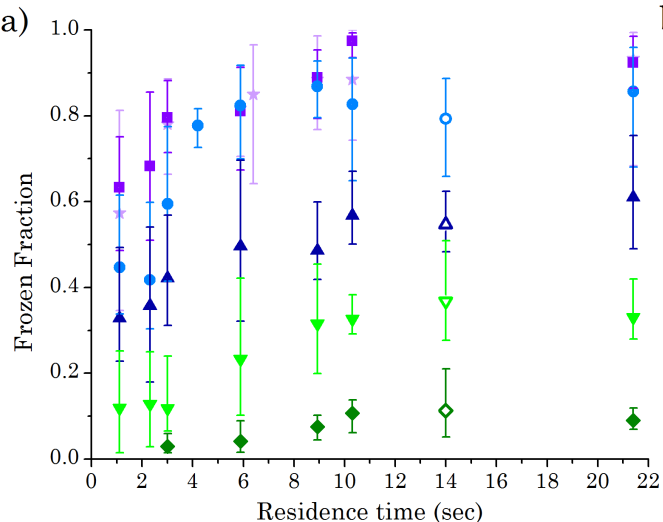

b)

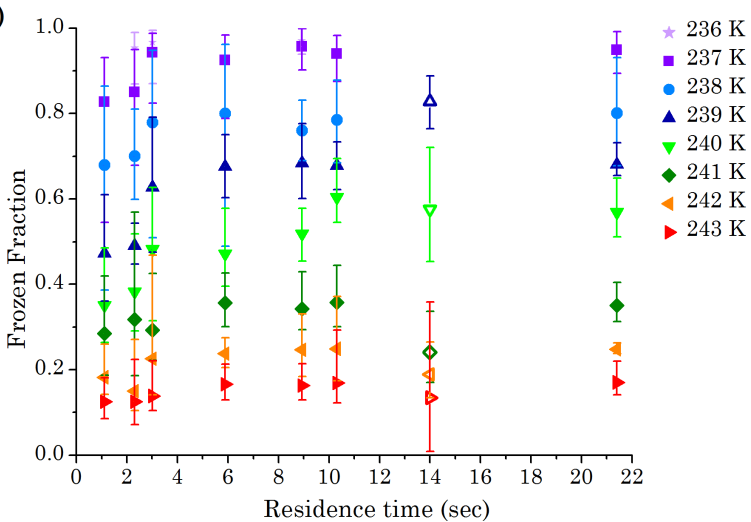

Fig. 5. Time dependent frozen fraction in the immersion mode for temperatures between $236 \mathrm{~K}$ and $243 \mathrm{~K}$. Each point represents an average of 3 to 7 measurements. a) shows the results for size selected $400 \mathrm{~nm}$ kaolinite particles and b) $800 \mathrm{~nm}$ kaolinite particles. For comparison, results reported in Lüönd et al. (2010) are shown as open symbols. Error bars represent the uncertainty in the frozen fraction due to the classification of particles as ice crystals or droplets (see Sect. 2.4 for details).

\subsection{Classical nucleation theory based models}

Classical nucleation theory is a stochastic approach to describe ice nucleation. CNT assumes that incipient ice clusters are continuously forming and disappearing with a temperature dependent frequency (Barnes et al., 1962). For heterogeneous nucleation, it predicts a probability per unit time and surface area for an ice cluster to reach critical size and initiate the freezing process. According to classical nucleation theory as for example formulated by Volmer and Weber (1926) or Fletcher (1969) (summarised in Pruppacher and Klett (1997)), the probability of occurrence of nucleation events can be described by heterogeneous nucleation rates calculated as

$$
\begin{array}{r}
J(T, \alpha)=\frac{k T}{h} \exp \left(-\frac{\Delta F_{\text {diff }}(T)}{k T}\right) . \\
n \cdot \exp \left(-\frac{\Delta G(T) f_{\text {het }}(\alpha)}{k T}\right)
\end{array}
$$

where $k$ is the Boltzmann constant, $h$ Planck's constant, $n$ the number density of water molecules at the interface of the IN with the surrounding liquid and $T$ is temperature. In the case of immersion freezing, the Gibbs free energy for the transfer of water molecules to the ice phase for the critical ice embryo formation is given by

$\Delta G(T)=\frac{16 \pi}{3} \frac{V_{\text {ice }}^{2}(T) \sigma_{\mathrm{i} / \mathrm{w}}^{3}(T)}{\left[k T \ln S_{i}(T)\right]^{2}}$,

where $V_{\text {ice }}(T)$ denotes the volume of a water molecule in the ice embryo and $\sigma_{\mathrm{i} / \mathrm{w}}(T)$ is the specific interfacial free energy (also called surface tension) between the ice embryo surface and the surrounding water droplet. $S_{i}$ is the ice saturation ratio which for immersion freezing is equal to the temperature dependent ratio of the saturation vapour pressure over water and ice.
The compatibility factor which describes the reduction in the free energy barrier as a function of the contact angle $\alpha$ (Chakraverty and Pound, 1964; Pruppacher and Klett, 1997) is

$$
f_{\text {het }}(\alpha)=(2+\cos \alpha)(1-\cos \alpha)^{2} / 4
$$

The formulas used to derive contact angles from the experimentally measured frozen fraction are summarized in the following Sects. 4.2.1 to 4.2.3. The complexity of the surface parameterisation increases from the purely stochastic, to $\alpha$ pdf and further to the active site model. The resulting contact angle distributions are shown in Fig. 6.

The diffusion energy barrier of a water molecule to cross the water/ice embryo interface is

$\Delta F_{\text {diff }}(T)=\frac{\partial \ln D_{l}(T)}{\partial T} k T^{2}$,

where $D_{l}(T)$ denotes the diffusivity of water. As $\Delta F_{\text {diff }}(T)$ is difficult to approach experimentally the parameterisation proposed in the work of Zobrist et al. (2007) is used.

\subsubsection{Stochastic model}

The particle surface is assumed to be smooth, uniform and equal for all particles. The free fitting parameter is the contact angle $\alpha$ which applies to all particles. A contact angle of $0^{\circ}$ reflects epitaxial ice formation whereas $180^{\circ}$ represents purely homogeneous nucleation. The frozen fraction is given by

$f_{\mathrm{i}, \text { stoch }}=1-\exp \left(-J(T, \alpha) 4 \pi r_{\mathrm{N}}^{2} t_{\mathrm{ZINC}}\right)$.

where $r_{\mathrm{N}}$ is the radius of the IN and $t_{\mathrm{ZINC}}$ is the residence time in the ZINC chamber. By minimizing the sum of square error between the experimentally measured frozen fraction and the frozen fraction calculated by Eq. (5) the best fitting contact angle can be derived. 


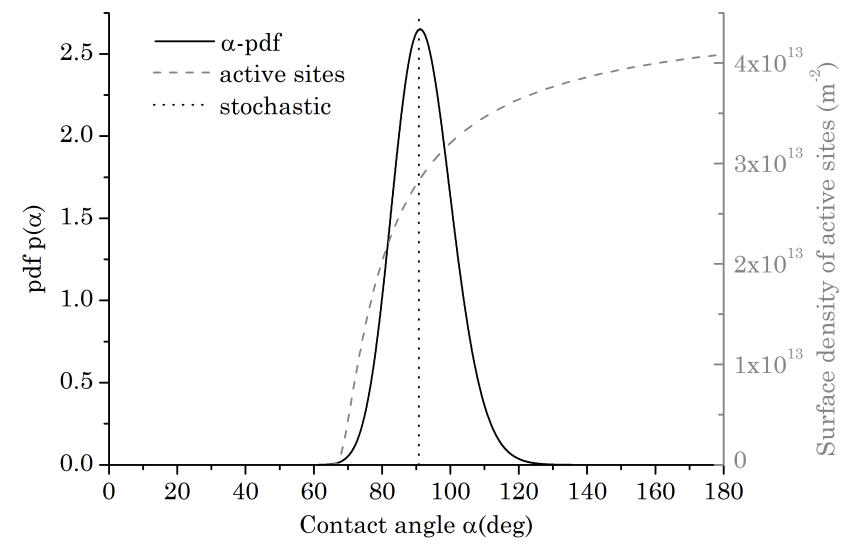

Fig. 6. Contact angle distribution on the particles.

\subsection{2 $\alpha$-pdf model}

The contact angle probability density function ( $\alpha$-pdf) approach takes into account the heterogeneity of individual particles in the sample. The particle surface is smooth and uniform for each particle but differs within an ensemble i.e. the contact angle $\alpha$ differs among the particle population.

The distribution of the contact angle occurrence among the particles of a population is assumed to be represented by a log-normal probability density function, given by

$p(\alpha)=\frac{1}{\alpha \sqrt{2 \pi \sigma^{2}}} \exp \left(-\frac{(\ln (\alpha)-\mu)^{2}}{2 \sigma^{2}}\right)$,

where $\mu$ is the mean contact angle and $\sigma^{2}$ is the variance. The frozen fraction for a given temperature can then be calculated as

$$
f_{\mathrm{i}, \alpha-\mathrm{pdf}}=1-\int_{0}^{\pi} p(\alpha) \cdot \exp \left(-J(T, \alpha) 4 \pi r_{N}^{2} t_{\mathrm{ZINC}}\right) d \alpha .
$$

Fit parameters $\mu$ and $\sigma$ are found by minimizing the sum of square errors of Eq. (7) with respect to the experimental data.

\subsubsection{Active site model}

The active site model takes into account that even the surface of individual particles might vary significantly with respect to their mineralogical surface composition and morphology. Therefore, instead of having a smooth surface, the model assumes that the aerosol is covered with surface inhomogeneities (active sites). A random distribution of active sites is assumed, each having an area of $A_{\alpha_{i}}=6 \mathrm{~nm}^{2}$ over the whole surface of each individual particle. $6 \mathrm{~nm}^{2}$ corresponds to the cross-sectional area of a critical embryo at $239 \mathrm{~K}$ (Lüönd et al., 2010). Each active site is assigned a contact angle. The surface density of contact angle values
Table 2. Fit parameters obtained for the four models described in Sects. 4.2-4.3. The root mean square errors (RMSE) between the fit curves and the data are given in the last column.

\begin{tabular}{lccc}
\hline Model & Parameter & Value & RMSE \\
\hline Stochastic & $\alpha$ & $90.75^{\circ}$ & 0.242 \\
$\alpha$-pdf & $\mu$ & $91.94^{\circ}$ & 0.111 \\
& $\sigma$ & 0.0942 & \\
Active sites & $b$ & $4.550 \times 10^{13} \mathrm{~m}^{-2}$ & 0.127 \\
& $\beta_{1}$ & $12.39^{\circ}$ & \\
& $\beta_{2}$ & $64.66^{\circ}$ & \\
Singular & $a_{1}$ & $8.569 \times 10^{10} \mathrm{~m}^{-2} \mathrm{~K}^{-2}$ & 0.156 \\
& $a_{2}$ & $242.65 \mathrm{~K}$ & \\
\hline
\end{tabular}

is defined according to Marcolli et al. (2007) by:

$\rho(\alpha)=b \cdot \exp \left(\frac{-\beta_{1}}{\alpha-\beta_{2}}\right)$,

where $b, \beta_{1}$ and $\beta_{2}$ are free fit parameters. Numerical values for the fit parameters are given in Table 2 and the resulting active site surface density as a function of contact angle is shown in Fig. 6.

The freezing probability of one droplet (index $j$ ) with one immersed particle during the residence time $t_{\mathrm{ZINC}}$ is calculated as one minus the probability that none of the randomly assigned active sites on the particle causes freezing, i.e.

$p_{\mathrm{frz}, \mathrm{j}}(T)=1-\prod_{i=1}^{m} \exp \left(-J\left(T, \alpha_{i}\right) A_{\alpha_{i}, j} t_{\mathrm{ZINC}}\right)$

where $m$ is the number of intervals of contact angles from $[0, \pi]$ (Lüönd et al., 2010). The frozen fraction of an ensemble of droplets containing individually varying particles is then calculated as the sum of the individual freezing probability of each droplet divided by the total number of droplets:

$f_{\mathrm{i}, \mathrm{AS}}=\frac{1}{N_{t o t}} \sum_{j=1}^{N_{\text {tot }}} p_{\mathrm{frz}, \mathrm{j}}(T)$.

A total number of $\mathrm{N}_{t o t}=1000$ droplets was used for the model. The parameters of $\rho(\alpha)$ are derived by minimizing the sum of the square errors between measurements and the function given in Eq. 10.

\subsection{Singular model}

The time-independent, singular or deterministic model as proposed in the work of Connolly et al. (2009) describes ice nucleation on active sites which become active at distinct temperatures. This approach is not based on CNT. The frozen fraction of droplets $f_{\mathrm{i} \text {, sing }}$ is given by

$f_{\mathrm{i}, \text { sing }}=1-\exp \left(-n_{S}(T) \cdot 4 \pi r_{\mathrm{N}}^{2}\right)$, 


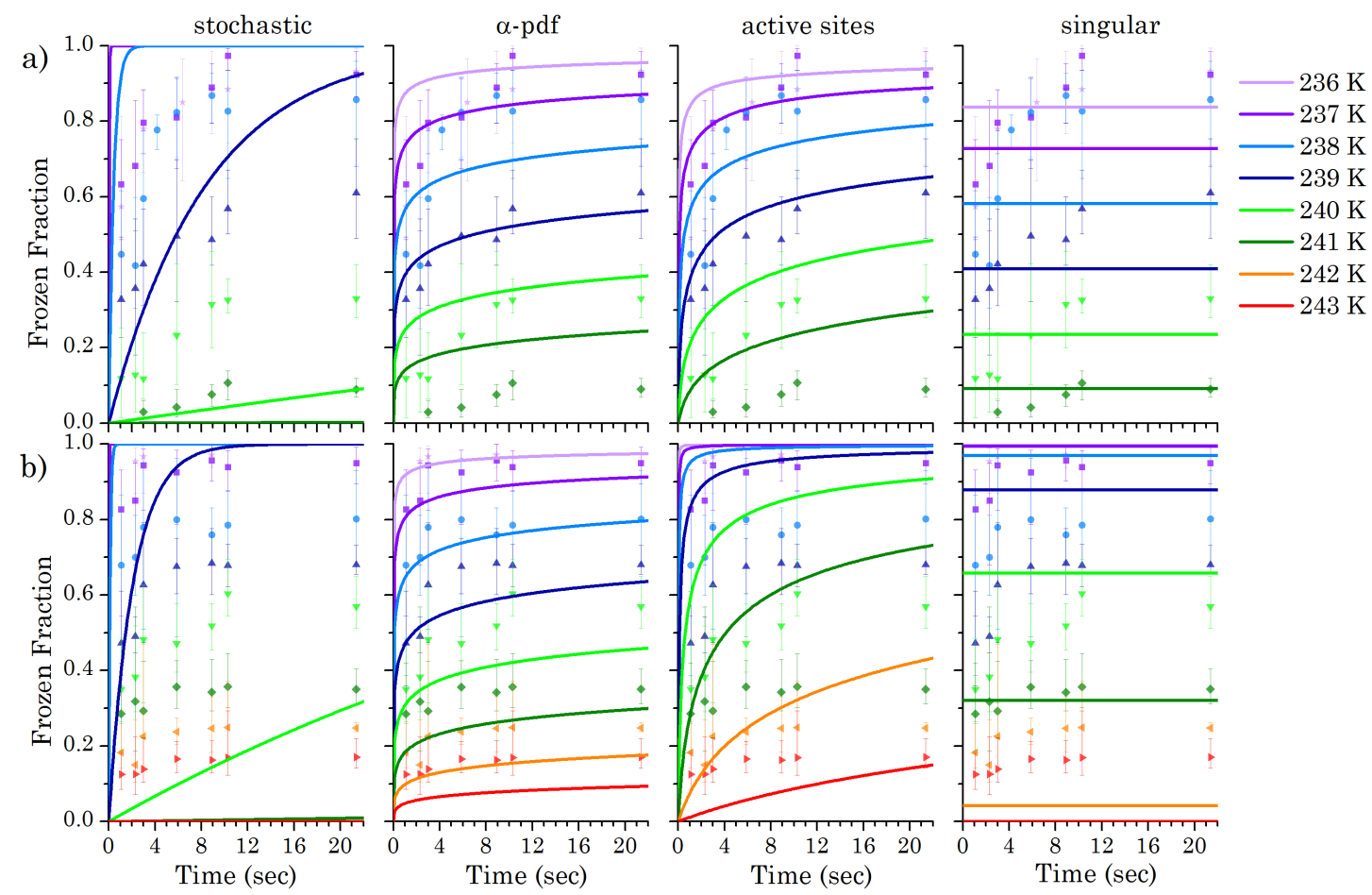

Fig. 7. Comparison of the fit curves obtained with the four models with experimental data. (a) $400 \mathrm{~nm}$ kaolinite particles. (b) $800 \mathrm{~nm}$ kaolinite particles. The parameters used to obtain the fit curves for both particle sizes are given in Table 2. The error bars represent the uncertainty in the distinction between water and ice with the IODE detector. See Sect. 2.4 for details.

where $n_{s}(T)$ denotes the surface density of sites active at a given temperature. To fit Eq. (11) to the data the following function proposed in Connolly et al. (2009) was used:

$n_{s}(T)= \begin{cases}a_{1}\left(T+a_{2}\right)^{2}, & T<a_{2} \\ 0, & T \geq a_{2}\end{cases}$

\subsection{Comparison of the models}

Applying the four models described in Sect. 4.2-4.3 to the experimental data we obtained the fit curves shown in Fig. 7. Best fit parameters obtained by the least square method are given in Table 2. The two models that combine a stochastic formation of the ice embryo with a distribution of surface properties ( $\alpha$-pdf and active site model) represent the experimental data best. The $\alpha$-pdf model represents the measurements slightly better than the active site model. This could indicate a relatively large variety of characteristics between individual particles rather than many diverse active sites on a given particle. Time dependence is less pronounced in the $\alpha$-pdf than in the active site model.

Also the singular approach adequately reproduces the frozen fraction within the $22 \mathrm{sec}$ of the experiment, but is unable to capture the observed increase in frozen fraction with time. Both active site models (singular and stochastic active site model) over predict the influence of the particle surface on freezing temperatures (q.v. Sect. 6.2). This however might also indicate an insufficient representation of the surface available for nucleation in the formulas used in this study. A stochastic fit to the measurements using a single contact angle is neither able to capture the time nor temperature dependence in an adequate manner. A figure showing the comparison of nucleation rates derived from the experimental data to the apparent nucleation rates as a function of temperature of all models is given in the supplementary material to this paper.

\section{Atmospheric implication}

To illustrate the difference in the predicted frozen fraction from different physical descriptions of the particle surface (single contact angle, $\alpha$-pdf, active sites) and germ formation process (stochastic, singular) we calculated the time evolution of a mixed-phase cloud and the dependence of the medium freezing temperature on the size of the particles. In these two applications, the importance of an appropriate description of ice nucleation in predicting ice formation becomes particularly apparent.

\subsection{Glaciation time of an isothermal water cloud}

Supercooled clouds have a finite lifetime in which ice nucleation can take place. To provide some information on the natural conditions for which the reported measurements are relevant, we used the four freezing models to extrapolate 


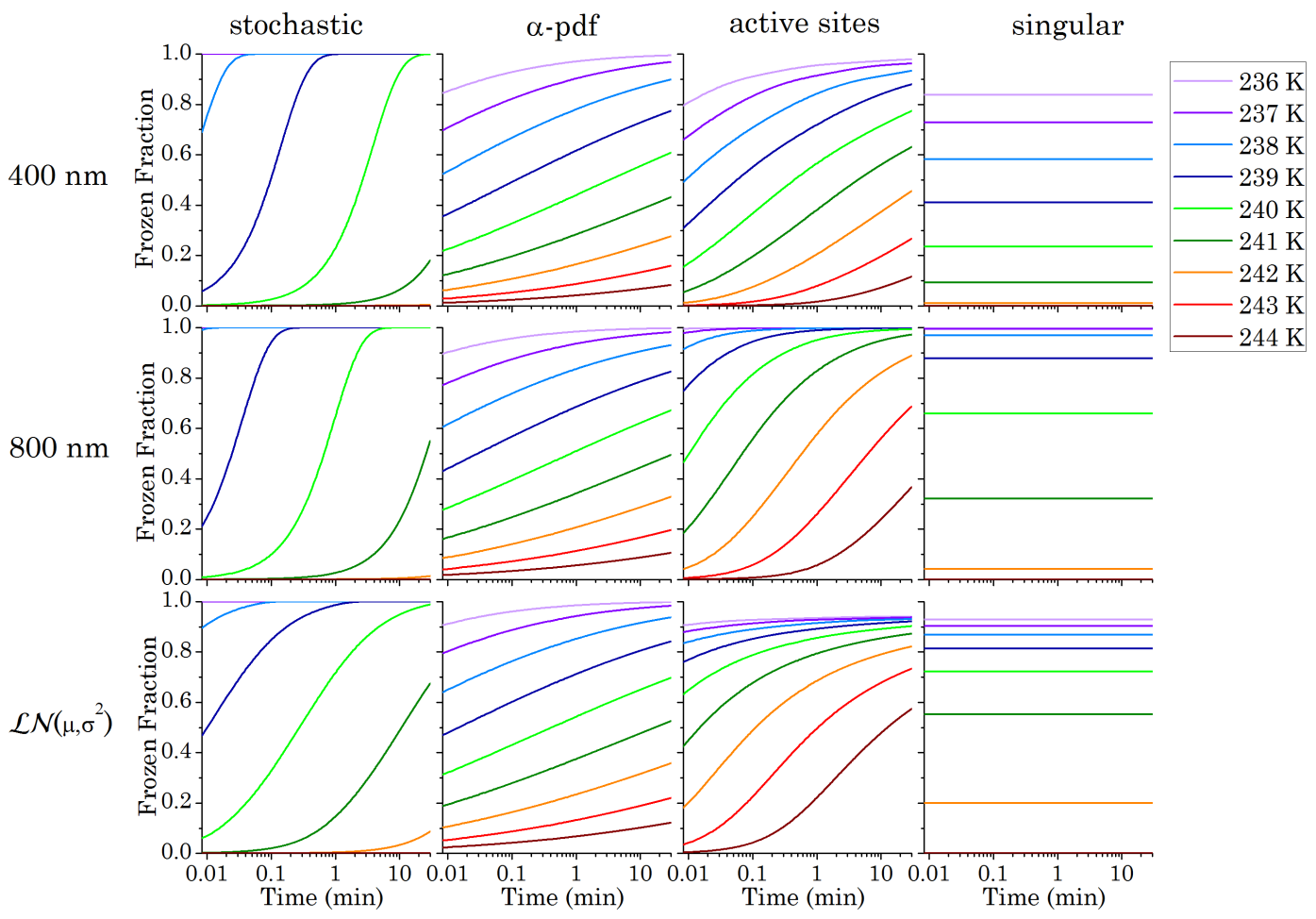

Fig. 8. Calculated increase in the frozen fraction with time for $400 \mathrm{~nm}, 800 \mathrm{~nm}$ monodisperse particles and for a particle ensemble exhibiting a log-normal size distribution with $\mu=600 \mathrm{~nm}$ and $\sigma^{2}=1$. The fitting parameters obtained in Sect. 4.1 for the four different models are applied to calculate a $30 \mathrm{~min}$ time evolution of the frozen fraction at temperatures between $236 \mathrm{~K}$ to $244 \mathrm{~K}$.

the freezing state of an isothermal cloud to an atmospheric timescale. We estimated the available glaciation time to be on the order of the timescale over which the Bergeron-Findeisen process would consume the liquid water content of a cloud consisting of $50 \%$ ice crystals and $50 \%$ droplets of 5-10 $\mu \mathrm{m}$ radius. From the $d^{2}$-law for evaporating droplets (Frohn and Roth, 2000) the cloud lifetime $\tau$ can be derived according to:

$\frac{d r_{\mathrm{drop}}^{2}(t)}{d t}=\underbrace{2 \cdot V_{\mathrm{m}, \mathrm{H}_{2} \mathrm{O}} \cdot D_{g}(T) \cdot\left(\frac{p_{\mathrm{i}}(T)-p_{\mathrm{w}}(T)}{R T}\right)}_{c}$

$\tau=\frac{-r_{\text {drop }}^{2}(t=0)}{c}$

where $r_{\text {drop }}$ denotes the radius of the liquid drop, $V_{\mathrm{m}, \mathrm{H}_{2} \mathrm{O}}$ the molar volume of water, $D_{g}(T)$ the temperature dependent water vapour diffusion coefficient, and $p_{\mathrm{i}}, p_{\mathrm{w}}$ the saturation vapour pressure over ice and water respectively.

The cloud lifetime $\tau$ has been estimated to be on the order of $30 \mathrm{~min}$. Using $\tau$ as a representative time scale available for ice nucleation in a mixed-phase cloud, the importance of time on the glaciation state becomes explicit. By applying the four different model approaches described previously, we calculate the time evolution of the frozen fraction over $30 \mathrm{~min}$. It can be seen from Fig. 8 that the choice of an accurate approach is fundamental to describe the glaciation of a mixed- phase cloud. The simple stochastic model is highly sensitive to the particle size, temperature and time. Taking into account a spectrum of contact angles as was done with the $\alpha$-pdf and active site model, lowers the dependence on temperature and time compared to the stochastic model. The influence of particle size on the $\alpha$-pdf model is a proportional shift to higher frozen fractions with increasing IN radius. Compared to the $\alpha$-pdf, the active site model predicts a steeper time dependence and increase of the frozen fraction for larger particle surface.

The rapid change in the frozen fraction for increasing residence time, calculated for the active site model with the probability density function taken from Marcolli et al. (2007) is unexpected, as this model, although also based on CNT, is conceptionally closer to the singular model than the $\alpha$-pdf or the stochastic model (cf. Fig. 10). Probably the assumption of a $6 \mathrm{~nm}^{2}$ active site area (Lüönd et al., 2010) and the resulting number of active sites generated per particle is too high (i.e. 335167 active sites on a $800 \mathrm{~nm}$ particle). Combined with the steep increase of the surface density function (Eq. 8), this might cause the particle population to appear too homogeneous i.e. little variation of the best active site present on a particle among the particle population. As preferentially the best active sites initiate freezing, the resulting time-dependent fit curves of the active sites model seems to 
resemble a stochastic nucleation which takes place on a single active site surface exhibiting an efficient contact angle.

By assuming a log-normal size distribution of the particles, we tested if the time dependence would be decreased by the variable activity of the different particle sizes. It can be seen in the lowest row of Fig. 8 that the size distribution causes the slope in the active site model to increase stronger in the beginning (resembling the stochastic freezing curve) and flattening out after a relatively short time. This indicates that a fraction of the larger particles has a high probability to host an efficient active site, that causes these particles to activate rapidly, whereas the fraction of smaller particles activates at a delay. The faster increase in frozen fraction of larger particles can also be seen when comparing the freezing curves for the monodisperse $400 \mathrm{~nm}$ and $800 \mathrm{~nm}$ particles. A bimodal size distribution i.e. a distribution with a second peak at larger sizes, might cause an even steeper increase in the beginning followed by a weak, flattening slope. Though being stochastic in nature, the initial rapid freezing of a fraction of droplets containing the larger aerosol mode followed by little additional freezing initiated by the smaller mode, could mimic a singular ice nucleation behaviour. As can be seen in the forth column of Fig. 8 for the singular, polydisperse case a reduction in the temperature dependence of the frozen fraction is predicted. The influence of the particle size distribution becomes important as the threshold temperature where a particle can serve as IN i.e. the occurrence of a site, active at that specific temperature, is proportional to the particle surface area. A size distribution therefore results in a higher frozen fraction even at high temperatures, due to the activation of large IN and a lower activation at lower temperatures in comparison to a monodisperse aerosol population.

\section{Discussion and Limitations}

Scanning electron microscope (SEM) pictures of the kaolinite sample (Fluka) used in this study can be found in Welti et al. (2009) and Ladino et al. (2011). The kaolinite particles are not spherical and exhibit rugged, stratified surfaces. Therefore, results for size selected particles are likely to represent a lower limit of the surface area of the particles used in this study. The geometric surface area was used instead of an approximately 3 to 6 times larger (for 400 and $800 \mathrm{~nm}$ particles respectively) $\mathrm{N}_{2}$ Brunauer-Emmett-Teller (BET) surface area for kaolinite as reported for example in Jiang et al. (2010). Due to the partly hydrophobic property of the mineral dust surface (Yin and Miller, 2012), the area where water can adsorb on a particle can be expected to be smaller than the surface occupied by nitrogen molecules (Zettlemoyer et al., 1961).

The ice nucleation efficiency of kaolinite is known to differ for samples from different sources. The kaolinite (Fluka) used in this study is known to initiate freezing at higher temperatures in comparison to other clay minerals (Pinti et al., 2012). With kaolinite particles, the current experimental setup and temperature range, a stochastic component of immersion freezing with a time exposure of up to $22 \mathrm{~s}$ was observed at temperatures within $8 \mathrm{~K}$ of homogeneous freezing temperature. For other IN species with a higher ice nucleating efficacy (due to the presence of active sites), which act as ice nuclei at smaller supercooling, the time dependence of immersion freezing can be expected to be less pronounced. This is due to the higher probability of stochastic ice cluster formation towards lower temperatures where the critical ice cluster size becomes smaller compared to higher temperatures. With decreasing size of the critical ice embryo towards homogeneous freezing temperatures, surface features (that might be more or less prominent on different IN samples and particles of different sizes), able to reduce the number of molecules needed for a stable ice cluster, become less important. Evidence for this effect can be found by comparing the time dependent frozen fraction of the experimental data with 400 to $800 \mathrm{~nm}$ particles where the latter shows a less pronounced increase in the frozen fraction with time of exposure. An example of the IN species dependent observability of time dependence, are the cold stage studies of Murray et al. (2011) and Broadley et al. (2012) both investigating immersion freezing of mineral dust IN with the same experimental setup. Murray et al. (2011) observed a stochastic behavior of ice nucleation on kaolinite (KGa-1b, Clay Mineral Society) particles with median freezing temperatures of $238 \mathrm{~K}$, whereas Broadley et al. (2012) found that measurements on illite NX with an approximately $6 \mathrm{~K}$ higher median freezing temperature were best described assuming a singular mechanism.

The IN activity could also be an impermanent feature, as from the moment the aerosols are released into the atmosphere until they become active in clouds they are exposed to sunlight and chemical compounds in the air that might lead to loss or increase of their nucleation activity (Cziczo et al., 2009; Yang et al., 2011; Chou et al., 2012), therefore the time dependence of nucleation on a single species could change with aging-time.

The different approaches to compute the frozen fraction with fit parameters gained from the measurements yield different dependencies on nucleation time. Using a timedependent, stochastic description of the nucleation mechanism in combination with the pdf-contact angle distribution leads to the best agreement with the experimental data in the temperature range of 236-243 K. Based on the findings of the current study we therefore recommend to include a time-dependence in numerical calculations of the evolution of mixed-phase clouds. In contrast to this recommendation Broadley et al. (2012) concluded that immersion freezing on illite NX occurs within a sufficiently short time to neglect the kinetic limitation of the nucleation mechanism to represent their experimental results. However in the sensitivity study by Ervens and Feingold (2012) exploring the variability in the frozen fraction obtained from model schemes 
similar to those used in the present study, it was concluded that the apparent consistency of laboratory results to diverse model schemes (time dependent or independent) is limited to the narrow time and temperature range under which the experiments were conducted. Consistent with the discussion in Sect. 5, they point out the importance of using a physically appropriate description of the nucleation mechanism when it is applied to atmospherically relevant scenarios. To compare the effect of time and temperature on the frozen fraction of immersion freezing on the kaolinite dust investigated in this study, we refer to the $\alpha$-pdf and active sites fit curves shown in Fig. 8, at a typical mixed-phase cloud temperature of $243 \mathrm{~K}$. A change in time scale by a factor of 10 results in approximately the same increase in frozen fraction as a shift in temperature by $1 \mathrm{~K}$. A small change in supercooling will therefore cause a much larger change in the frozen fraction than a change in the nucleation time. This implies that temperature is more important than time in determining immersion freezing. This is in agreement with the findings of Vali (2008).

\subsection{Temperature dependent, apparent contact angle}

In CNT, the contact angle is usually assumed to be a constant which depends only on the properties of the substrate on which nucleation is initiated. Using Eq. (2-3) and the stochastic model (Eq. 5) we calculated the contact angle as a function of temperature for each individual experiment. The resulting contact angles are given in Fig. 9. Calculating the apparent contact angle of each individual measurement with CNT revealed a nearly linear relationship of the contact angle with temperature. This temperature dependence represents the deviations of the experimental results from the predictions of the stochastic model. The increase in the apparent median contact angle can be interpreted as evidence for an increase in the importance of the nucleation kinetics to ice formation as the temperature of homogeneous freezing is approached i.e. a decrease in the reduction of the Gibbs free energy for nucleation by the compatibility factor $f_{\text {het }}(\alpha)$. Surface features lowering the contact angle of an ice embryo to the substrate become increasingly important towards higher temperatures.

Particles with small contact angles are able to initiate nucleation at higher temperatures than particles with larger contact angles. $\alpha(\mathrm{T})$ reflects the mean active contact angle at a certain temperature without giving information about how the contact angles are distributed among the particles. Alpert et al. (2011) pointed out that according to Young's equation (Pruppacher and Klett, 1997) a temperature dependence of contact angle $\alpha$ could be expected due to the temperature dependence of the surface tensions between the substrate, water and ice phase. The Young equation gives the relation between contact angle of immersion freezing and the thereby involved

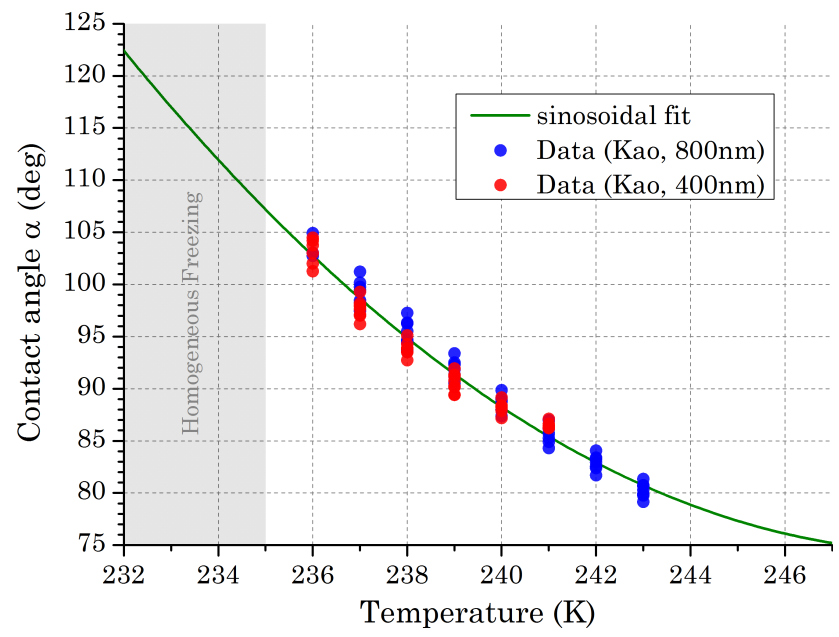

Fig. 9. Contact angle vs. temperature for $400 \mathrm{~nm}$ and $800 \mathrm{~nm}$ kaolinite particles in the immersion mode. Calculated using classical nucleation theory.

surface tensions:

$\cos (\alpha(T))=\frac{\sigma_{\mathrm{s} / \mathrm{a}}(T)-\sigma_{s / i}(T)}{\sigma_{\mathrm{i} / \mathrm{w}}(T)}$

here $\alpha(T)$ is the contact angle and $\sigma_{\mathrm{s} / \mathrm{a}}(T), \sigma_{S / i}(T), \sigma_{\mathrm{i} / \mathrm{w}}(T)$ the temperature dependent surface tensions between the kaolinite surface and water, the surface and ice, and between ice and water, respectively. By using the temperature dependent mean contact angle, a value for $\sigma_{\mathrm{s} / \mathrm{a}}$ reported in Helmy et al. (2004) and the parametrisation of $\sigma_{\mathrm{i} / \mathrm{w}}(T)$ which can be found in Pruppacher and Klett (1997) the surface tension between the ice germ and the kaolinite substrate $\left(\sigma_{S / i}\right)$ can be derived. We find reasonable values of $\sigma_{s / i}(243 \mathrm{~K}) \approx 0.078 \mathrm{Jm}^{-2}$ increasing by $0.0013 \mathrm{Jm}^{-2} \mathrm{~K}^{-1}$ towards lower temperatures. This test confirms that it is plausible to attribute a change in contact angle to a change in surface tension with temperature. However, to conclude on the physical meaning of this finding, is out of scope of this study.

We conclude, that as particles with high contact angles become active at lower temperatures the average active contact angle of a population could be parameterised as temperature dependent within the stochastic model. This might be a simple way to parameterize immersion freezing in climate models without applying calculation intense surface parameterisations. A comparison between the frozen fraction predicted by the $\alpha(T)$ approach and the time dependent experimental data can be found in the supplementary material.

\subsection{Surface area dependence of the mean freezing temperature}

A comparison (shown in Fig. 10) of the surface area dependent median freezing temperature (50\% of drops unfrozen) obtained from the four previously described models 


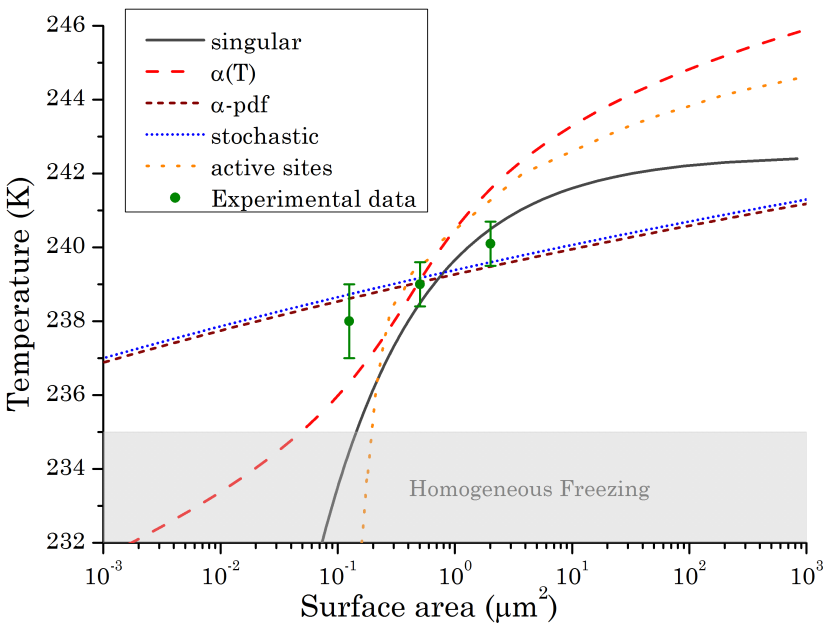

Fig. 10. Surface area dependent median freezing temperature i.e. temperature at which a kaolinite particle with the corresponding surface area will nucleate ice in immersion mode with a probability of $50 \%$. In a population of droplets this corresponds to $50 \%$ frozen droplets. Nucleation time is $10 \mathrm{~s}$.

and from the temperature dependent contact angle parametrisation, revealed a large variation in the prediction of the particle surface area required to freeze $50 \%$ of a droplet population. Measurements of droplets containing several particles as done e.g. in DSC and cold stage studies, could provide information on the surface dependent median freezing temperature for larger available surface areas. This information could be of value for modelling studies e.g. Diehl and Wurzler (2004) and Lohmann and Diehl (2006) have used median freezing temperatures to compute droplet freezing rates in their climate models.

\section{Conclusions}

The ability of kaolinite particles to act as IN under mixedphase cloud condition and the importance of nucleation time have been investigated in the immersion mode.

Size selected $400 \mathrm{~nm}$ and $800 \mathrm{~nm}$ kaolinite particles have been found to initiate ice formation in the immersion mode within a temperature range of $236-243 \mathrm{~K}$ and exposure times of 1-22 s. A dependence of the frozen fraction from immersion freezing on time has been observed. This confirms that immersion freezing is at least partly a stochastic phenomenon. For the atmosphere this means that the droplets of a supercooled cloud continue to transform to ice even without further cooling. This has been observed in static supercooled clouds which persist for hours (Crosier et al., 2011).

Because larger particles have a larger contact area to the liquid phase or a higher probability of carrying efficient nucleation sites, the minimum supercooling to activate them as IN is smaller than for smaller particles. Beside the particle size, the temperature has a strong influence on the time re- quired for droplets to freeze. The exponential dependence of the nucleation rate on temperature in the framework of CNT, indicates that there is virtually no freezing above a certain temperature, except for very long lived clouds or huge particles. The experiments reported here, show that smaller particles need more time to nucleate ice at a given temperature than larger particles i.e. the influence of time on the frozen fraction is stronger the smaller the particles are and becomes most evident at the onset temperature of immersion freezing. Similar conclusions have been reached for AgI particles by Vonnegut (1949) and Gerber (1976).

It follows that measurements of the concentrations of particles able to act as IN in a particular experiment or atmospheric process have to be qualified with respect to the particle size and both the available time to freeze and the temperature, as has been called for before e.g. by Vonnegut (1987).

We used time-dependent and one time-independent model to investigate their applicability to describe the measured frozen fraction from the experiment. The models yield essential variances. A purely stochastic model diverges substantially from the measurement. It over predicts the time evolution as well as the temperature dependence of immersion freezing. The singular model is able to fit the frozen fraction in the limited nucleation time but over predicts the effect of particle size on the temperature of freezing. Modified stochastic models ( $\alpha$-pdf and active site) capture the temperature and time-dependent ice fraction well. However, also these two models are not able to fit the measurements within the experimental error. Revised contact angle distribution functions might benefit the model accuracy. Nonetheless, a lack of knowledge on the correlation between the surface structure and the nucleation ability makes it difficult to find an appropriate description on a microscopic scale.

The results presented here are dependent on the applicability of Eq. (8) (Marcolli et al., 2007) or Eq. (12) (Connolly et al., 2009). E.g. the function by which the active site density is described in the active site model might look completely different. If active sites were distributed over the range of contact angles according to a bimodal distribution with two distinctly separated maxima, e.g. due to the presence of two different properties that aid nucleation, time dependence would be masked by rapid activation of particles with the efficient property and extremely slow activation of particles with the inefficient one. The resulting evolution in time at a constant temperature would mimic singular behaviour. Generally a wide distribution of properties (surface area or chemical) among particles found in a cloud might create a more singular freezing behaviour than a narrow distribution around the same average. This is in agreement with the model results of Niedermeier et al. (2011) and the experimental results of Broadley et al. (2012).

To definitively conclude whether single active sites or the surface structure of the entire IN are responsible for immersion freezing is not possible based on the data available in this study. The fact that the nucleation activity can be 
described appropriately by assuming a contact angle distribution over the whole particle ensemble might indicate that average properties are better suited for parameterisations. To further investigate if there are active sites or more uniformly distributed properties that are responsible for the nucleation process, the effect of surface area could be studied for a large range of particle diameters $(10 \mathrm{~nm}-10 \mu \mathrm{m})$. Such dataset would allow to test the surface area dependency predicted by the two approaches (shown in Fig. 10).

A combination of a less broad distribution of contact angles than reported in Sect. 4 among an ensemble of particle together with a temperature dependence (for example of $\sim 2^{\circ} K^{-1}$ or as an additional free parameter) could be tested to take into account the temperature dependence of contact angles in combination with a contact angle distribution.

\section{Supplementary material related to this article is available online at: http://www.atmos-chem-phys.net/12/ 9893/2012/acp-12-9893-2012-supplement.pdf.}

Acknowledgements. We acknowledge financial support from the Swiss National Funds (SNF).

Edited by: M. Petters

\section{References}

Alpert, P., Aller, J., and Knopf, D.: Initiation of the ice phase by marine biogenic surfaces in supersaturated gas and supercooled aqueous phases, Phys. Chem. Chem. Phys., 13, 19882-19894, doi:10.1039/c1cp21844a, 2011.

Ansmann, A., Tesche, M., Seifert, P., Althausen, D. andEngelmann, R., Fruntke, J., Wandinger, U., Mattis, I., and Müller, D.: Evolution of the ice phase in tropical altocumulus: SAMUM lidar observations over Cape Verde, J. Geophys. Res., 114, D17208, doi:10.1029/2008JD011659, 2009.

Barnes, G. T., Katz, U., and Sänger, R.: Ice Forming Activity and the Surface Properties of Nucleating Materials, ZAMP, 13, 7680, 1962.

Bigg, E.: The Supercooling of Water, Proc. Phys. Soc. B, 66, 688694, 1953.

Broadley, S. L., Murray, B. J., Herbert, R. J., Atkinson, J. D., Dobbie, S., Malkin, T. L., Condliffe, E., and Neve, L.: Immersion mode heterogeneous ice nucleation by an illite rich powder representative of atmospheric mineral dust, Atmos. Chem. Phys., 12, 287-307, doi:10.5194/acp-12-287-2012, 2012.

Bunker, K. W., China, S., Mazzoleni, C., Kostinski, A., and Cantrell, W.: Measurements of ice nucleation by mineral dusts in the contact mode, Atmos. Chem. Phys. Discuss., 12, 2029120309, doi:10.5194/acpd-12-20291-2012, 2012.

Cantrell, W. and Heymsfield, A.: Production of ice in tropospheric clouds, B. Am. Meteorol. Soc., BAMS-86-6-795, 795806, 2005.
Chakraverty, B. and Pound, G.: Heterogeneous Nucleation at Macroscopic Steps, Acta Metallurg., 12, 851-860, 1964.

Chou, C., Stetzer, O., Tritscher, T., Chirico, R., Heringa, M. F., Kanji, Z. A., Weingartner, E., Prévôt, A. S. H., Baltensperger, U., and Lohmann, U.: Effect of photochemical aging on the ice nucleation properties of diesel and wood burning particles, Atmos. Chem. Phys. Discuss., 12, 14697-14726, doi:10.5194/acpd-1214697-2012, 2012.

Connolly, P. J., Möhler, O., Field, P. R., Saathoff, H., Burgess, R., Choularton, T., and Gallagher, M.: Studies of heterogeneous freezing by three different desert dust samples, Atmos. Chem. Phys., 9, 2805-2824, doi:10.5194/acp-9-2805-2009, 2009.

Crosier, J., Bower, K. N., Choularton, T. W., Westbrook, C. D., Connolly, P. J., Cui, Z. Q., Crawford, I. P., Capes, G. L., Coe, H., Dorsey, J. R., Williams, P. I., Illingworth, A. J., Gallagher, M. W., and Blyth, A. M.: Observations of ice multiplication in a weakly convective cell embedded in supercooled mid-level stratus, Atmos. Chem. Phys., 11, 257-273, doi:10.5194/acp-11-257-2011, 2011.

Cziczo, D. J., Froyd, K. D., Gallavardin, S. J., Moehler, O., Benz, S., Saathoff, H., and Murphy, D. M.: Deactivation of ice nuclei due to atmospherically relevant surface coatings, Environ. Res. Lett., 4, 044013 ,doi:10.1088/1748-9326/4/4/044013, 2009.

DeMott, P., Sassen, K., Poellot, M., Baumgardner, D., Rogers, D., Brooks, S., Prenni, A., and S. M., K.: African dust aerosols as atmospheric ice nuclei, Geophys. Res. Lett., 30, 1732, doi:10.1029/2003GL017410, 2003 b.

Diehl, K. and Wurzler, S.: Heterogeneous Drop Freezing in the Immersion Mode: Model Calculations Considering Soluble and Insoluble Particles in the Drops, J. Atmos. Sci., 61, 2063-272, 2004.

Earle, M. E., Kuhn, T., Khalizov, A. F., and Sloan, J. J.: Volume nucleation rates for homogeneous freezing in supercooled water microdroplets: results from a combined experimental and modelling approach, Atmos. Chem. Phys., 10, 7945-7961, doi:10.5194/acp-10-7945-2010, 2010.

Eastwood, M., Cremel, S., Gehrke, C., Girard, E., and Bertram, A. K.: Ice nucleation on mineral dust particles: Onset conditions, nucleation rates and contact angles, J. Geophys. Res., 113, D22203, doi:10.1029/2008JD010639, 2008.

Ervens, B. and Feingold, G.: On the representation of immersion and condensation freezing in cloud models using different nucleation schemes, Atmos. Chem. Phys., 12, 5807-5826, doi:10.5194/acp-12-5807-2012, 2012.

Fletcher, N.: On Ice-Crystal Production by Aerosol Particles, J. Meteor., 16, 173-180, 1959.

Fletcher, N.: Active Sites and Ice Crystal Nucleation, J. Atmos. Sci., 26, 1266-1271, 1969.

Frohn, A. and Roth, N.: Dynamics of Droplets, Springer Berlin/Heidelberg, 2000.

Gerber, H.: Relation of size and activity of AgI smoke particles, J. Atmos. Sci., 33, 667-677, 1976.

Helmy, A. K., Ferreiro, E. A., and de Bussetti, S. G.: The surface energy of kaolinite, Colloid Polym. Sci., 283, 225-228, 2004.

Hoose, C., Kristjánsson, J., Chen, J., and Hazra, A.: A ClassicalTheory-Based Parameterization of Heterogeneous Ice Nucleation by Mineral Dust, Soot, and Biological Particles in a Global Climate Model, J. Atmos. Sci., 67, 2483-2503, 2010. 
Houghton, H. G.: A preliminary quantitative analysis of precipitation mechanisms, J. Meteor., 7, 363-369, 1950.

Isono, K., Komabayasi, M., and Ono, A.: The nature and origin of ice nuclei in the atmosphere, J. Meteorol. Soc. Jpn., 37, 211-233, 1959.

Jiang, T., Hirasaki, G., and Miller, C.: Characterization of Kaolinite $\zeta$ Potential for Interpretation of Wettability Alteration in Diluted Bitumen Emulsion Separation, Energy Fuels, 24, 23502360, 2010.

Kumai, M.: Electron-microscope study of snow-crystal nuclei, J. Atmos. Sci., 8, 151-156, 1951.

Ladino, L., Stetzer, O., Lüönd, F., Welti, A., and Lohmann, U.: Contact freezing experiments of kaolinite particles with cloud droplets, J. Geophys. Res., 116, D22202, doi:10.1029/2011JD015727, 2011.

Langham, E. and Mason, B.: The heterogeneous and homogeneous nucleation of supercooled water, Proc. Roy. Soc., A247, 493504, 1958.

Lohmann, U.: A glaciation indirect aerosol effect caused by soot aerosols, Geophys. Res. Lett., 29, 1052, doi:10.1029/2001GL014357, 2002.

Lohmann, U. and Diehl, K.: Sensitivity Studies of the Importance of Dust Ice Nucleation for the Indirect Aerosol Effect on Stratiform Mixed-Phase Clouds, J. Atmos. Sci., 63, 968-982, 2006.

Lüönd, F., Stetzer, O., Welti, A., and Lohmann, U.: Experimental study on the ice nucleation ability of size-selected kaolinite particles in the immersion mode, J. Geophys. Res., 115, D14201, doi:10.1029/2009JD012959, 2010.

Marcolli, C., Gedamke, S., Peter, T., and Zobrist, B.: Efficiency of immersion mode ice nucleation on surrogates of mineral dust, Atmos. Chem. Phys., 7, 5081-5091, doi:10.5194/acp-7-50812007, 2007.

Murray, B., Broadley, S., Wilson, T., Atkinson, J., and Wills, R.: Heterogeneous freezing of water droplets containing kaolinite particles, Atmos. Chem. Phys., 11, 4191-4207, doi:10.5194/acp11-4191-2011, 2011.

Nicolet, M., Stetzer, O., Lüönd, F., Möhler, O., and Lohmann, U.: Single ice crystal measurements during nucleation experiments with the depolarization detector IODE, Atmos. Chem. Phys., 10, 313-325, doi:10.5194/acp-10-313-2010, 2010.

Niedermeier, D., Shaw, R. A., Hartmann, S., Wex, H., Clauss, T., Voigtländer, J., and Stratmann, F.: Heterogeneous ice nucleation: exploring the transition from stochastic to singular freezing behavior, Atmos. Chem. Phys., 11, 8767-8775, doi:10.5194/acp11-8767-2011, 2011.

Pinti, V., Marcolli, C., Zobrist, B., Hoyle, C. R., and Peter, T.: Ice nucleation efficiency of clay minerals in the immersion mode, Atmos. Chem. Phys., 12, 5859-5878, doi:10.5194/acp-12-58592012, 2012.

Pruppacher, H. and Klett, J.: Microphysics of clouds and precipitation, Springer Netherlands, 954 pp., 1997.

Rogers, D.: Development of a Continuous Flow Thermal Gradient Diffusion Chamber for Ice Nucleation Studies, Atmos. Res., 22, 149-181, 1988.
Sassen, K. and Wang, Z.: The Clouds of the Middle Troposphere: Composition, Radiative Impact, and Global Distribution, Surv. Geophys., 33, 677-691, 2012.

Stetzer, O., Baschek, B., Luond, F., and Lohmann, U.: The Zurich Ice Nucleation Chamber (ZINC) - A new instrument to investigate atmospheric ice formation, Aerosol Sci. Technol., 42, 6474, 2008.

Vali, G.: Nucleation terminology, J. Aerosol Sci., 16, 575-576, 1985.

Vali, G.: Freezing Rate Due to Heterogeneous Nucleation, J. Atmos. Sci., 51, 13, 1843-1856, 1994.

Vali, G.: Repeatability and randomness in heterogeneous nucleation, Atmos. Chem. Phys., 8, 5017-5031, doi:10.5194/acp-85017-2008, 2008.

Vali, G. and Stansbury, E.: Time-Dependent Characteristics of the Heterogeneous Nucleation of Ice, Canadian J. Phys., 44, 477$502,1966$.

Volmer, M. and Weber, A.: Keimbildung in übersättigten Gebilden, Z. phys. Chem., 119, 277-301, 1926.

Vonnegut, B.: Nucleation of supercooled water clouds by silver iodide smokes, Chemical reviews, 44, 277-289, 1949.

Vonnegut, B.: Importance of Including Time in the Specification of Ice Nucleus Concentration, J.Climate Appl. Meteorol., 26, p. $322,1987$.

Wartburton, J. and Heffernan, K.: Time Lag in Ice Crystal Nucleation by Silver Iodide, J. Appl. Meteorol., 3, 788-791, 1964.

Welti, A., Lüönd, F., Stetzer, O., and Lohmann, U.: Influence of particle size on the ice nucleating ability of mineral dusts, Atmos. Chem. Phys., 9, 6705-6715, doi:10.5194/acp-9-6705-2009, 2009.

Westbrook, C. and Illingworth, A.: Stochastic ice nucleation in supercooled clouds, and constraints on the fraction of small ice crystals in glaciated clouds, observed using Doppler lidar and radar, in: 8th ISTP, 2009.

Wiacek, A. and Peter, T.: On the availability of uncoated mineral dust ice nuclei in cold cloud regions, Geophys. Res. Lett., 36, L17801, doi:10.1029/2009GL039429, 2009.

Yang, Z., Bertram, A., and Chou, K.: Why Do Sulfuric Acid Coatings Influence the Ice Nucleation Properties of Mineral Dust Particles in the Atmosphere?, J. Phys. Chem. Lett., 2, 1232-1236, 2011.

Yin, X. and Miller, J.: Wettability of kaolinite basal planes based on surface measurements using atomic force microscopy, Minerals Metallurg. Proc., 29, 13-19, 2012.

Zettlemoyer, A., Tcheurekdjian, N., and Chessick, J.: Surface Properties of Silver Iodide, Nature, 18, p. 653, 1961.

Zhang, D., Wang, Z., and Liu, D.: A global view of midlevel liquidlayer topped stratiform cloud distribution and phase partition from CALIPSO and CloudSat measurements, J. Geophys. Res., 115, D00H13, doi:10.1029/2009JD012143, 2010.

Zobrist, B., Koop, T., Luo, B. P., Marcolli, C., and Peter, T.: Heterogeneous ice nucleation rate coefficient of water droplets coated by a nonadecanol monolayer, J. Phys. Chem. C, 111, 2149-2155, 2007. 